\title{
The variation in the health status of immigrants and Italians during the global crisis and the role of socioeconomic factors
}

\author{
Alessio Petrelli ${ }^{1 *} \mathbb{D}$, Anteo Di Napoli ${ }^{1}$, Alessandra Rossi ${ }^{1}$, Gianfranco Costanzo ${ }^{1}$, Concetta Mirisola ${ }^{1}$ \\ and Lidia Gargiulo²
}

\begin{abstract}
Background: The effects of the recent global economic and financial crisis especially affected the most vulnerable social groups. Objective of the study was to investigate variation of self-perceived health status in Italians and immigrants during the economic global crisis, focusing on demographic and socioeconomic factors.

Methods: Through a cross-sectional design we analyzed the national sample of multipurpose surveys "Health conditions and use of health services" (2005 and 2013) conducted by the Italian National Institute of Statistics (ISTAT). Physical Component Summary (PCS) and Mental Component Summary (MCS) scores, derived from SF-12 questionnaire, were assumed as study outcome, dichotomizing variables distribution at $1^{\text {st }}$ quartile. Prevalence rate ratios (PRR) were estimated through log-binomial regression models, stratified by citizenship and gender, evaluating the association between PCS and MCS with surveys' year, adjusting for age, educational level, employment status, self-perceived economic resources, smoking habits, body mass index.
\end{abstract}

Results: From 2005 to 2013 the proportion of people not employed or reporting scarce/insufficient economic resources increased, especially among men, in particular immigrants. Compared with 2005 we observed in 2013 among Italians a significant lower probability of worse PCS (PRR $=0.96$ both for males and females), while no differences were observed among immigrants; a higher probability of worse MCS was observed, particularly among men (Italians: PRR $=1.26 ; 95 \% \mathrm{Cl}: 1.22-1.29 ;$ immigrants: PRR $=1.19 ; 95 \% \mathrm{Cl}: 1.03-1.38$ ). Self-perceived scarce/ insufficient economic resources were strongly and significantly associated with worse PCS and MCS for all subgroups. Lower educational level was strongly associated with worse PCS in Italians and slightly associated with worse MCS for all subgroups. Being not employed was associated with worse health status, especially mental health among men.

Conclusions: Our findings support the hypothesis that economic global crisis could have negatively affected health status, particularly mental health, of Italians and immigrants. Furthermore, results suggest socioeconomic inequalities increase, in economic resources availability dimension. In a context of public health resources' limitation due to financial crisis, policy decision makers and health service managers must face the challenge of equity in health.

Keywords: Immigrants, Socioeconomic, Health inequalities, Economic global crisis, Italy, Survey

\footnotetext{
* Correspondence: petrelli@inmp.it

'National Institute for Health, Migration and Poverty (INMP), Via San

Gallicano, 25 a, 00153 Rome, Italy

Full list of author information is available at the end of the article
} International License (http://creativecommons.org/licenses/by/4.0/), which permits unrestricted use, distribution, and reproduction in any medium, provided you give appropriate credit to the original author(s) and the source, provide a link to the Creative Commons license, and indicate if changes were made. The Creative Commons Public Domain Dedication waiver (http://creativecommons.org/publicdomain/zero/1.0/) applies to the data made available in this article, unless otherwise stated. 


\section{Background}

Migration flows from developing countries towards Europe and Italy in particular, both for economic reasons and to flee war and persecution, has increased in the past few years. In particular, in the period 2013-2015, about half million people reached the Italian coasts: out of them, about $40 \%$ applied for international protection [1].

In Italy, the most recent estimates from the Italian National Institute of Statistics indicate that the number of resident immigrants has doubled in the last decade, from 2.4 million people ( $4.1 \%$ of the resident population) in 2005 to 5 million (8.2\% of the resident population) in 2015 [2], of which $52.7 \%$ females. The average age is 31.1 for males and 34.1 for females. Out of them, almost 3.5 million (70.3\%) are non-EU citizens: $22.7 \%$ from European countries, 20.5\% from Africa, 19\% from Asia and about $8 \%$ from the other continents [3]. The most represented immigrant groups in Italy are from Romania (22.6\%), Albania (9.8\%), Morocco (9.0\%), China (5.3\%) and Ukraine (4.5\%).

First generation immigrants generally have better health conditions than the resident population. Two factors can act in determining this observation: the 'healthy migrant effect', the natural selection determining higher tendency to migrate in younger or healthier people $[4,5]$, and the selection in the return to the country of origin (salmon bias) $[6,7]$. The relative role of this selective strength has not been clarified, while recent evidence from Europe tend to support the healthy migrant effect [8-11]. However, this health advantage tends to decrease once in the host country [12], socioeconomic difficulties that immigrants usually experience, accentuated by greater limitation in social mobility and discrimination [13], and also for assimilation of most deprived population lifestyle.

The effects of the recent global economic and financial crisis especially affected the most vulnerable social groups [14], to which most of immigrants belong. Between 2008 and 2013, employment significantly decreased, especially amongst immigrants (-9\% compared to $-2.5 \%$ amongst Italians), contributing to deepen socioeconomic inequalities [15].

Many studies showed that the adverse effects of the crisis on population's health, although with different intensity and elasticity, mostly affected non-developed countries, where welfare systems are weaker, and disadvantaged populations, in which the major social health risks, such as unemployment and poverty, are generally present [16, 17]. In this sense, the economic crisis emphasized socioeconomic health inequalities [18, 19]. Moreover, austerity policies, adopted in many countries to face the crisis, further exposed these particularly vulnerable populations to such disadvantages [20].

It is widely recognised that conditions of greater deprivation can negatively influence health outcomes
[21, 22], both in physical [23-25] and mental [26] terms. There is significant evidence supporting an association between loss of employment and economic resources and mental health worsening [27, 28]. Negative effects on mental health were particularly observed among immigrants, who are more greatly affected by the increase of unemployment [19].

In Italy, some studies investigated the health of immigrants [29-31]; however, as far as we know, no evidence are available about the health status of Italians and immigrants during the recent global economic crisis on.

The National Institute for Health, Migration and Poverty (INMP) monitors the health status of disadvantaged population groups and perform scientific research through manages its National Epidemiologic Observatory on Immigrants and Poverty (OENIP). INMP started an institutional collaboration with the Italian National Institute of Statistics (ISTAT)., ISTAT carried out multipurpose surveys aimed at evaluating Italian and immigrant resident people's health and use of health services in 2005 and 2013, so just before and after global economic crisis. In this sense we could indirectly observe the potential effect of the crisis on the health status of the population.

The aim of the present study was to compare the variation in the health status of Italians and immigrants between 2005 and 2013 by evaluating the self-perception of physical and mental health, and exploring the role of demographic and socioeconomic factors.

\section{Methods}

This study was based on data of the multipurpose survey "Health conditions and use of health services" of 2013 and 2005 carried out by ISTAT on a representative sample of people residing in Italy. Two stage sampling method was used: in the first stage municipalities were firstly stratified into large cities and small towns and villages. All the large cities were included, while small towns and villages were selected with probability proportional to their size. In the second stage, families were selected with random criterion from the municipal registry lists. All the components of each selected families were included in the sample. The survey collected information on health conditions, health determinants and use of health services.

In both editions, data collection was carried out in four different surveys, conducted every three months. This method was aimed at taking into account the seasonal effects affecting health. Information was collected through PAPI (Paper and Pencil Interview) interviews to each member of the de facto family, conducted at the family home by interviewers trained by ISTAT. Some information was collected through self-administered individual questionnaires [32].

The sample is composed of families residing in Italy (2013 $n=48,811 ; 2005 n=50,474)$ and their members 
(2013 $n=119,073 ; 2005 n=128,041)$. The 2013 survey was conducted from July 2012 to June 2013, and the 2005 edition from October 2004 to September 2005.

As present study refers to working age people, we only took into account the sub-sample of people aged between 18 and 64 (in $2013 n=72.476$ and in $2005 n=80.661$ ), which represents a population of $37,290,440$ people resident in Italy $(33,900,000$ Italians and 3,390,440 immigrants) in 2013, and of 36,852,745 (35,040,000 Italians and $1,812,745$ immigrants) in 2005.

Immigrant status was defined using information about citizenship, dichotomized in two categories: Italian and foreigner.

In order to measure self-perception of health, two health status indexes were used: Physical Component Summary (PCS) and Mental Component Summary (MCS), both derived from the Short Form Health Survey (SF-12) and largely used in a number of empirical studies on European populations. SF-12 contains twelve questions on eight different dimensions related to health: physical activity, work limitations for health reasons, emotional state, physical pain, self-perceived general health, vitality, social activities and mental health [33].

Very low PCS values indicate poor physical health, limited self-care and physical, social and personal activity, serious physical pain. On the other hand, very high PCS values indicate excellent physical health without physical limitations, disability and reduction of general wellbeing and high vitality. We considered as status of worse physical health a PCS value up to the $1^{\text {st }}$ quartile of its total distribution in the population studied in the two survey editions. The cut-off was PCS value equal to 52 .

Very low MCS values indicate poor mental health with frequent psychological discomfort, significant social and personal disability due to emotional problems. On the other hand, very high MCS levels indicate excellent mental health with frequent positive psychological attitude, absence of psychological discomfort and of limitations to social and personal activities due to emotional problems. We considered as worse physical health status a MCS value up to the $1^{\text {st }}$ quartile of its total distribution in the population studied in the two survey editions. The cut-off was MCS value equal to 46 .

The PCS and MCS distribution at $1^{\text {st }}$ quartile cannot be interpreted as the prevalence of bad health status and does not have any diagnostic implication on the health status.

We estimated prevalence rate ratios (PRR) by using logbinomial regression models and dichotomised MCS and PCS as outcome variables to evaluate the association with survey's edition (2005/2013), age group (18-34, 35-49, 50-64), level of education (high, medium, low), employment (yes/not), self-perceived economic resources (excellent/adequate, scarce/insufficient), smoking habits (never smoked, former smoker, smoker), body mass index (normal weight, underweight, overweight/obese). Each regression model was stratified by gender and citizenship (Italians/immigrants).

The socioeconomic covariates were progressively included in the models. Following interactions were also tested: a) socioeconomic covariates and citizenship; b) survey's edition and citizenship; c) survey's edition and socioeconomic factors. All analyses were performed using not weighted sample data. Statistical analysis was performed with SAS System 9.3.

\section{Results}

Table 1 summarises some socio-demographic, clinical and lifestyle characteristics of Italians and immigrants respectively, stratified by gender, and compares the results of the 2013 and the 2005 survey. Out of total residents aged 1864 , immigrants in the sample are more than doubled, from $3.2 \%$ in 2005 to $7.1 \%$ in 2013 . In relative terms, the immigrant population in the age group 50-64 increased from $11.2 \%$ in 2005 to $18.1 \%$ in 2013 (relative increase $60.9 \%$ ), whereas Italians from 30.8 to $35.3 \%$ (relative increase $14.4 \%)$. This apparently faster ageing of foreigners is attributable to the fact that, on average, those who migrated more recently were older.

During the study period, socioeconomic conditions worsened, especially among men, particularly immigrants. The number of not employed men in the considered sample is much more increased among immigrants (from 10.7 to $26.0 \%$, relative increase of $142.4 \%$ ) than Italians (from 26.1 to $32.4 \%$, relative increase of $24.4 \%$ ). The increase of not employed people was lower amongst women, in relative terms higher amongst immigrants than Italians (7.6\% vs $2.2 \%)$.

The percentage of immigrants reporting scarce/insufficient economic resources was much higher than Italians, both in 2005 (51.3\% vs 28.6\%) and 2013 (62.4\% vs $37.5 \%)$, even though in relative terms the increase was higher amongst Italians (31.1\% vs $21.5 \%$ for immigrants).

It is to be noted how this worsening in socioeconomic conditions took place notwithstanding the increase of people with higher educational level both among immigrants (from 36.7 to $41.3 \%$, relative increase of $12.8 \%$ ) and Italians (from 43.9 to $52.6 \%$, relative increase of $20.0 \%$ ).

There was a slight increase in overweight and obesity amongst the Italians between 2005-2013 (from 40.8 to $41.9 \%$, relative increase of $2.8 \%$ ). Whereas such increase was more significant amongst immigrants, both men (from 45.2 to $49.2 \%$ ) and women (from 27.8 to $35 \%$ ), amongst whom a higher variation in relative terms was reported ( $26.0 \%$ vs $8.8 \%$ amongst men).

The percentage of smokers slightly diminished, especially among immigrants, who smoked less than Italians in 2013 (23.5\% vs $25.7 \%)$. 
Table 1 Comparison between characteristics of population and year, by citizenship and gender

\begin{tabular}{|c|c|c|c|c|c|c|c|c|c|c|c|}
\hline \multirow[t]{3}{*}{ Variable } & & \multicolumn{5}{|l|}{ Italians } & \multicolumn{5}{|c|}{ Immigrants } \\
\hline & & \multicolumn{2}{|l|}{2005} & \multicolumn{2}{|l|}{2013} & \multirow[b]{2}{*}{$p$ value } & \multicolumn{2}{|l|}{2005} & \multicolumn{2}{|l|}{2013} & \multirow[b]{2}{*}{$p$ value } \\
\hline & & $n$ & $\%$ & $n$ & $\%$ & & $\mathrm{n}$ & $\%$ & $n$ & $\%$ & \\
\hline \multicolumn{12}{|l|}{ Men } \\
\hline$n$ & & 38,581 & & 33,355 & & & 1,203 & & 2,302 & & \\
\hline PCS & I quartile & 9,756 & 25.3 & 8,367 & 25.1 & n.s. & 220 & 18.3 & 465 & 20.2 & n.s. \\
\hline MCS & I quartile & 7,277 & 18.9 & 8,513 & 25.5 & $<.0001$ & 216 & 18.0 & 551 & 23.9 & $<.0001$ \\
\hline \multirow[t]{3}{*}{ Age } & $18-34$ & 12,985 & 33.7 & 9,512 & 28.5 & $<.0001$ & 554 & 46.1 & 924 & 40.1 & $<.0001$ \\
\hline & $35-49$ & 13,833 & 35.9 & 12,227 & 36.7 & & 540 & 44.9 & 1,028 & 44.7 & \\
\hline & $50-64$ & 11,763 & 30.5 & 11,616 & 34.8 & & 109 & 9.1 & 350 & 15.2 & \\
\hline \multirow[t]{3}{*}{ Educational level } & High & 16,551 & 42.9 & 17,014 & 51.0 & $<.0001$ & 386 & 32.1 & 823 & 35.8 & $<.0001$ \\
\hline & Medium & 16,779 & 43.5 & 14,161 & 42.5 & & 584 & 48.6 & 1,213 & 52.7 & \\
\hline & Low & 5,251 & 13.6 & 2,180 & 6.5 & & 233 & 19.4 & 266 & 11.6 & \\
\hline \multirow[t]{2}{*}{ Occupational status } & Employed & 28,524 & 73.9 & 22,541 & 67.6 & $<.0001$ & 1,074 & 89.3 & 1,704 & 74.0 & $<.0001$ \\
\hline & Unemployed & 10,057 & 26.1 & 10,814 & 32.4 & & 129 & 10.7 & 598 & 26.0 & \\
\hline \multirow[t]{2}{*}{ Self-perceived economic resources } & Excellent/adequate & 27,840 & 72.2 & 20,978 & 62.9 & $<.0001$ & 525 & 43.6 & 817 & 35.5 & $<.0001$ \\
\hline & Scarce/insufficient & 10,741 & 27.8 & 12,377 & 37.1 & & 678 & 56.4 & 1,485 & 64.5 & \\
\hline \multirow[t]{3}{*}{ Smoking habits } & Never smoked & 16,403 & 42.5 & 14,277 & 42.8 & n.s. & 592 & 49.2 & 1,135 & 49.3 & n.s. \\
\hline & Former smoker & 9,797 & 25.4 & 8,553 & 25.6 & & 206 & 17.1 & 419 & 18.2 & \\
\hline & Smoker & 12,381 & 32.1 & 10,525 & 31.6 & & 405 & 33.7 & 748 & 32.5 & \\
\hline \multirow[t]{3}{*}{ BMl } & Normal weight & 18,503 & 48.0 & 15,605 & 46.8 & $<0.001$ & 644 & 53.5 & 1,148 & 49.9 & n.s. \\
\hline & Underweight & 343 & 0.9 & 255 & 0.8 & & 15 & 1.3 & 21 & 0.9 & \\
\hline & Overweight/obese & 19,735 & 51.2 & 17,495 & 52.5 & & 544 & 45.2 & 1,133 & 49.2 & \\
\hline \multicolumn{12}{|l|}{ Women } \\
\hline$n$ & & 39,469 & & 33,940 & & & 1,408 & & 2,879 & & \\
\hline PCS & I quartile & 12,585 & 31.9 & 10,533 & 31.0 & $<0.01$ & 354 & 25.1 & 795 & 27.6 & n.s. \\
\hline MCS & I quartile & 11,046 & 28.0 & 11,228 & 33.1 & $<.0001$ & 311 & 22.1 & 786 & 27.3 & $<0.001$ \\
\hline \multirow[t]{3}{*}{ Age } & $18-34$ & 12,850 & 32.6 & 9,077 & 26.7 & $<.0001$ & 644 & 45.7 & 1,095 & 38.0 & $<.0001$ \\
\hline & $35-49$ & 14,332 & 36.3 & 12,751 & 37.6 & & 580 & 41.2 & 1,199 & 41.7 & \\
\hline & $50-64$ & 12,287 & 31.1 & 12,112 & 35.7 & & 184 & 13.1 & 585 & 20.3 & \\
\hline \multirow[t]{3}{*}{ Educational level } & High & 17,680 & 44.8 & 18,408 & 54.2 & $<.0001$ & 571 & 40.6 & 1,319 & 45.8 & $<.0001$ \\
\hline & Medium & 14,601 & 37.0 & 12,369 & 36.4 & & 608 & 43.2 & 1,258 & 43.7 & \\
\hline & Low & 7,188 & 18.2 & 3,163 & 9.3 & & 229 & 16.3 & 302 & 10.5 & \\
\hline \multirow[t]{2}{*}{ Occupational status } & Employed & 18,949 & 48.0 & 15,914 & 46.9 & $<0.01$ & 747 & 53.1 & 1,425 & 49.5 & $<0.05$ \\
\hline & Unemployed & 20,520 & 52.0 & 18,026 & 53.1 & & 661 & 47.0 & 1,454 & 50.5 & \\
\hline \multirow[t]{2}{*}{ Self-perceived economic resources } & Excellent/adequate & 27,911 & 70.7 & 21,109 & 62.2 & $<.0001$ & 746 & 53.0 & 1,133 & 39.4 & $<.0001$ \\
\hline & Scarce/insufficient & 11,558 & 29.3 & 12,831 & 37.8 & & 662 & 47.0 & 1,746 & 60.7 & \\
\hline \multirow[t]{3}{*}{ Smoking habits } & Never smoked & 25,208 & 63.9 & 21,239 & 62.6 & $<.0001$ & 981 & 69.7 & 2,058 & 71.5 & n.s. \\
\hline & Former smoker & 6,197 & 15.7 & 5,931 & 17.5 & & 180 & 12.8 & 354 & 12.3 & \\
\hline & Smoker & 8,064 & 20.4 & 6,770 & 20.0 & & 247 & 17.5 & 467 & 16.2 & \\
\hline BMl & Normal weight & 24,818 & 62.9 & 21,083 & 62.1 & $<0.01$ & 922 & 65.5 & 1,730 & 60.1 & $<.0001$ \\
\hline & Underweight & 2,561 & 6.5 & 2,128 & 6.3 & & 95 & 6.8 & 142 & 4.9 & \\
\hline & Overweight/obese & 12,090 & 30.6 & 10,729 & 31.6 & & 391 & 27.8 & 1,007 & 35.0 & \\
\hline
\end{tabular}


Figure 1 shows the distribution of PCS for Italian and immigrant men and women in 2005 and 2013. Among men, we observed similar median PCS values both in immigrants and Italians in 2005 (55.9 vs 55.5) and in 2013 (both 56.0). Among women, median PCS values were similar in 2005 (55.7 vs 55.3) and slightly higher for immigrants than Italians in 2013 (56.0 vs 55.0).

Figure 2 shows the distribution of MCS for Italian and immigrant men and women, in 2005 and 2013. Among men, median MCS values were similar for immigrants and Italians (53.6 vs 53.0). Among women, median MCS values decreased from 2005 to 2013 both for Italians (52.6 vs 51.0 ) and immigrants ( 52.8 vs 52.0 ).

Table 2 shows the results of the multivariate logbinomial model analysing factors associated with low PCS levels (PCS value $\leq 1^{\text {st }}$ quartile), stratified by citizenship and gender.

Compared to 2005, in 2013 we observed lower PRR of worse self-perceived physical health among Italians, while no differences were observed among immigrants, both for men and women. No interaction was observed between year and citizenship. It was observed that PRR increases with age in all considered groups. Furthermore, we observed a direct linear trend between education level and PCS among Italians $(p<0.05)$. An association between low educational level and a lower PCS was only observed in immigrant women. Italian and immigrant women showed a higher probability of $\mathrm{PCS}<=1^{\text {st }}$ quartile if not employed. Self-perceived scarce/insufficient economic resources are significantly associated with lower PCS levels in all the considered groups. All socioeconomic covariates appear to be independent factors for PCS (data not shown). Being a smoker or former-smoker is a condition independently associated with worse self-perceived physical health. Being overweight or obese is associated with higher probability of a worse self-perceived physical health, stronger among women than men, whereas an association with being underweight was only observed amongst Italian men.

Table 3 shows the results of the multivariate log-binomial model analysing factors associated with low MCS levels (MCS value $\leq 1^{\text {st }}$ quartile), stratified by citizenship and gender.

Compared with 2005, in 2013 we observed lower PRR of self-perceived mental health for all the considered groups, particularly among men. No interaction was observed between year and citizenship. Higher probability of lower self-perceived mental health was observed with age increasing in all considered groups. We observed an association between low educational level and higher probability of MCS $<=1^{\text {st }}$ quartile. Not employed men presented a higher PRR of mental health status, while no association was found for immigrant women. Self-perceived scarce/insufficient economic resources are the strongest predictor of $\mathrm{MCS}<=1^{\text {st }}$ quartile: all the considered groups show a probability higher than $40 \%$. All socioeconomic covariates appear to be independent factors for MCS (data not shown). Being a smoker or former-smoker is a condition independently associated with worse self-perceived mental health. Not being in normal weight is associated with higher probability of a worse self-perceived mental health only among Italian women, while an association with being underweight was only observed amongst Italian men.

\section{Discussion}

The results of our study, based on a representative sample of population residing in Italy, showed a worsening in the mental health status between 2005 and 2013, both among Italians and immigrants, also taking into account the effect of age, socioeconomic and lifestyle factors,

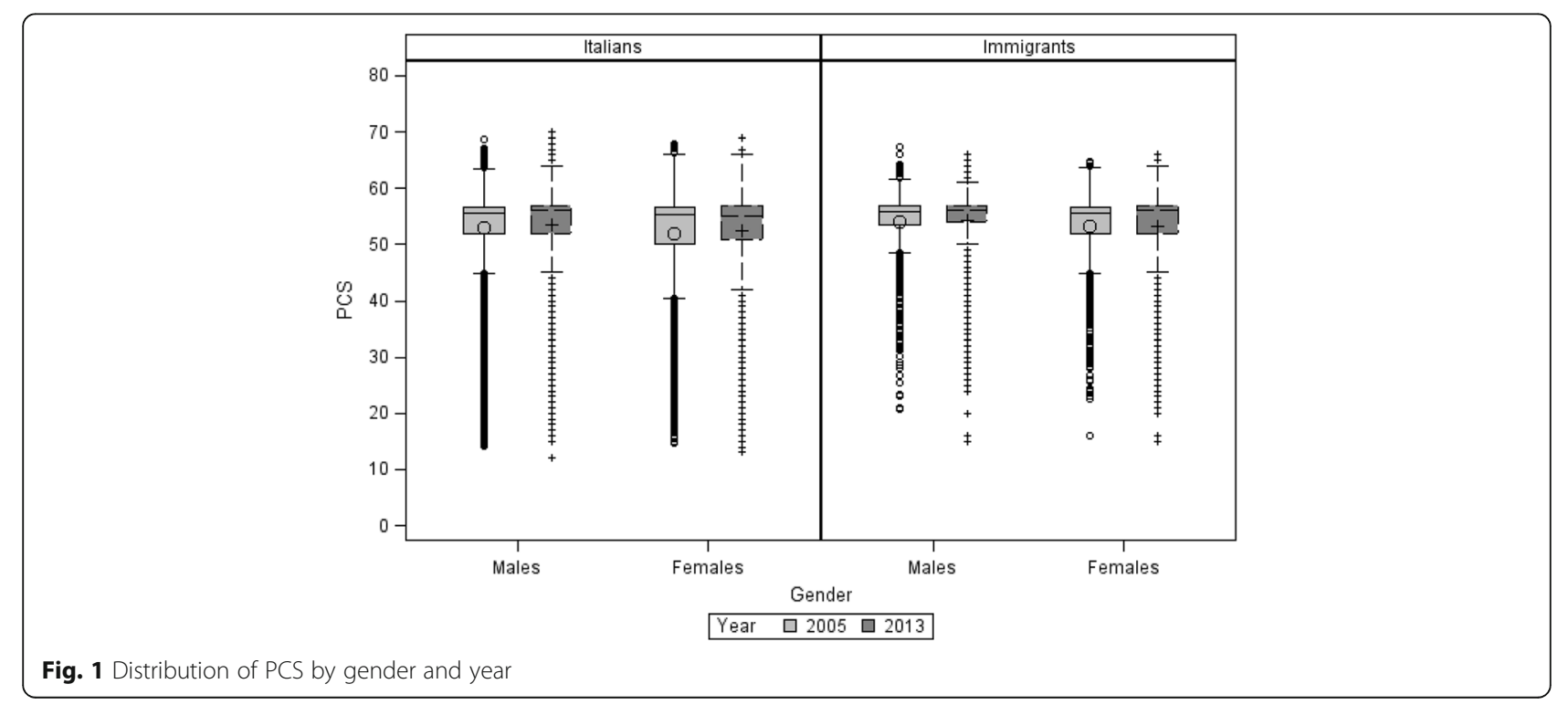




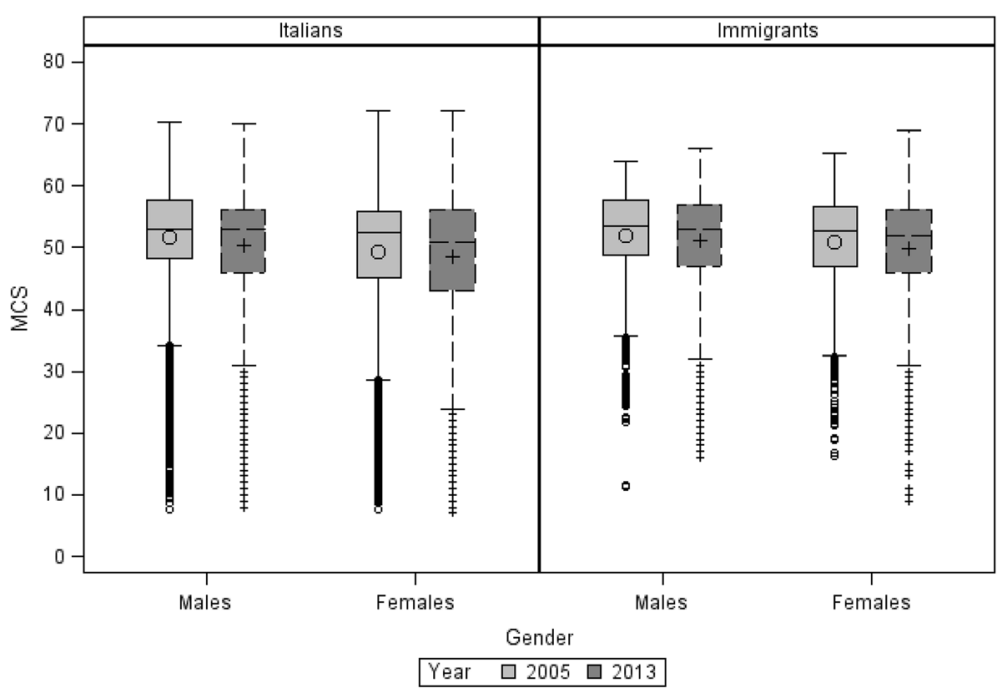

Fig. 2 Distribution of MCS by gender and year

while we did not observe significant differences in physical health status in the same period.

In this context, our findings support the hypothesis that the worsening of socioeconomic conditions observed during this period could have contributed to mental health decline [19], particularly amongst immigrants [34], as our data refer to years just before and after global economic crisis. Conversely to what was observed in Spain, a country with similar socioeconomic characteristics as Italy [35], we did not find any increase in differences in poor self-perceived mental health amongst immigrant women compared with natives.

Regarding physical health, a slight improvement was only observed among Italians. According to some studies,

Table 2 Factors associated to the probability to have worse self-perceived physical health (I quartile PCS), by gender and citizenship

\begin{tabular}{|c|c|c|c|c|c|c|c|c|c|c|c|c|c|}
\hline \multirow{4}{*}{$\begin{array}{l}\text { Variable } \\
\\
\text { Year }\end{array}$} & \multirow[b]{4}{*}{2005} & \multicolumn{6}{|c|}{ Men } & \multicolumn{6}{|c|}{ Women } \\
\hline & & \multicolumn{3}{|c|}{ Italians } & \multicolumn{3}{|c|}{ Immigrants } & \multicolumn{3}{|c|}{ Italians } & \multicolumn{3}{|c|}{ Immigrants } \\
\hline & & \multirow{2}{*}{$\begin{array}{l}\text { PRR } \\
1\end{array}$} & \multicolumn{2}{|c|}{ IC 95\% } & \multirow{2}{*}{$\begin{array}{l}\text { PRR } \\
1\end{array}$} & \multicolumn{2}{|c|}{ IC 95\% } & \multirow{2}{*}{$\begin{array}{l}\text { PRR } \\
1\end{array}$} & \multicolumn{2}{|c|}{ IC 95\% } & \multirow{2}{*}{$\begin{array}{l}\text { PRR } \\
1\end{array}$} & \multicolumn{2}{|c|}{ IC 95\% } \\
\hline & & & - & - & & - & - & & - & - & & - & - \\
\hline & 2013 & 0.96 & 0.94 & 0.99 & 1.03 & 0.89 & 1.19 & 0.96 & 0.94 & 0.98 & 1.00 & 0.90 & 1.12 \\
\hline \multirow[t]{3}{*}{ Age } & $18-34$ & 1 & - & - & 1 & - & - & 1 & - & - & 1 & - & - \\
\hline & $35-49$ & 1.59 & 1.52 & 1.65 & 1.36 & 1.15 & 1.60 & 1.50 & 1.45 & 1.56 & 1.20 & 1.07 & 1.36 \\
\hline & $50-64$ & 2.24 & 2.15 & 2.33 & 2.18 & 1.80 & 2.63 & 2.22 & 2.14 & 2.30 & 1.68 & 1.47 & 1.93 \\
\hline \multirow[t]{3}{*}{ Educational level } & High & 1 & - & - & 1 & - & - & 1 & - & - & 1 & - & - \\
\hline & Medium & 1.24 & 1.21 & 1.28 & 0.94 & 0.81 & 1.09 & 1.16 & 1.13 & 1.19 & 0.98 & 0.88 & 1.09 \\
\hline & Low & 1.45 & 1.40 & 1.50 & 0.98 & 0.80 & 1.20 & 1.34 & 1.30 & 1.39 & 1.18 & 1.03 & 1.36 \\
\hline \multirow[t]{2}{*}{ Occupational status } & Employed & 1 & - & - & 1 & - & - & 1 & - & - & 1 & - & - \\
\hline & Not employed & 1.21 & 1.18 & 1.24 & 0.99 & 0.84 & 1.17 & 1.05 & 1.03 & 1.07 & 1.10 & 1.00 & 1.22 \\
\hline \multirow[t]{2}{*}{ Self-perceived economic resources } & Excellent/adequate & 1 & - & - & 1 & - & - & 1 & - & - & 1 & - & - \\
\hline & Scarce/insufficient & 1.24 & 1.21 & 1.27 & 1.27 & 1.10 & 1.47 & 1.18 & 1.16 & 1.20 & 1.17 & 1.06 & 1.30 \\
\hline \multirow[t]{3}{*}{ Smoking habits } & Never smoked & 1 & - & - & 1 & - & - & 1 & - & - & 1 & - & - \\
\hline & Former smoker & 1.28 & 1.24 & 1.32 & 1.38 & 1.17 & 1.64 & 1.19 & 1.16 & 1.22 & 1.30 & 1.14 & 1.48 \\
\hline & Smoker & 1.10 & 1.06 & 1.13 & 1.24 & 1.07 & 1.45 & 1.09 & 1.06 & 1.12 & 1.16 & 1.02 & 1.32 \\
\hline \multirow[t]{3}{*}{ BMl } & Normal weight & 1 & - & - & 1 & - & - & 1 & - & - & 1 & - & - \\
\hline & Underweight & 1.35 & 1.19 & 1.54 & 1.04 & 0.46 & 2.35 & 1.02 & 0.97 & 1.08 & 0.97 & 0.75 & 1.26 \\
\hline & Overweight/obese & 1.13 & 1.10 & 1.16 & 1.18 & 1.02 & 1.35 & 1.25 & 1.22 & 1.28 & 1.29 & 1.17 & 1.43 \\
\hline
\end{tabular}


Table 3 Factors associated to the probability to have worse self-perceived mental health (I quartile MCS), by gender and citizenship

\begin{tabular}{|c|c|c|c|c|c|c|c|c|c|c|c|c|c|}
\hline \multirow[b]{4}{*}{ Year } & \multirow[b]{4}{*}{2005} & \multicolumn{6}{|l|}{ Men } & \multicolumn{6}{|c|}{ Women } \\
\hline & & \multicolumn{3}{|c|}{ Italians } & \multicolumn{3}{|c|}{ Immigrants } & \multicolumn{3}{|c|}{ Italians } & \multicolumn{3}{|c|}{ Immigrants } \\
\hline & & \multirow{2}{*}{$\begin{array}{l}\text { PRR } \\
1\end{array}$} & \multicolumn{2}{|c|}{ IC 95\% } & \multirow{2}{*}{$\begin{array}{l}\text { PRR } \\
1\end{array}$} & \multicolumn{2}{|c|}{ IC 95\% } & \multirow{2}{*}{$\begin{array}{l}\text { PRR } \\
1\end{array}$} & \multicolumn{2}{|c|}{ IC 95\% } & \multirow{2}{*}{$\begin{array}{l}\text { PRR } \\
1\end{array}$} & \multicolumn{2}{|c|}{ IC 95\% } \\
\hline & & & - & - & & - & - & & - & - & & - & - \\
\hline & 2013 & 1.26 & 1.22 & 1.29 & 1.19 & 1.03 & 1.38 & 1.13 & 1.11 & 1.16 & 1.17 & 1.05 & 1.32 \\
\hline \multirow[t]{3}{*}{ Age } & $18-34$ & 1 & - & - & 1 & - & - & 1 & - & - & 1 & - & - \\
\hline & $35-49$ & 1.40 & 1.35 & 1.46 & 1.16 & 1.00 & 1.33 & 1.16 & 1.12 & 1.19 & 1.19 & 1.06 & 1.34 \\
\hline & $50-64$ & 1.51 & 1.45 & 1.57 & 1.42 & 1.19 & 1.70 & 1.29 & 1.25 & 1.33 & 1.23 & 1.07 & 1.43 \\
\hline \multirow[t]{3}{*}{ Educational level } & High & 1 & - & - & 1 & - & - & 1 & - & - & 1 & - & - \\
\hline & Medium & 0.98 & 0.95 & 1.01 & 1.02 & 0.88 & 1.17 & 0.98 & 0.95 & 1.00 & 0.95 & 0.86 & 1.07 \\
\hline & Low & 1.08 & 1.03 & 1.13 & 1.17 & 0.98 & 1.41 & 1.10 & 1.07 & 1.14 & 1.17 & 1.01 & 1.37 \\
\hline \multirow[t]{2}{*}{ Occupational status } & Employed & 1 & - & - & 1 & - & - & 1 & - & - & 1 & - & - \\
\hline & Not employed & 1.32 & 1.28 & 1.36 & 1.54 & 1.35 & 1.76 & 1.04 & 1.02 & 1.07 & 0.98 & 0.88 & 1.08 \\
\hline \multirow[t]{2}{*}{ Self-perceived economic resources } & Excellent/adequate & 1 & - & - & 1 & - & - & 1 & - & - & 1 & - & - \\
\hline & Scarce/insufficient & 1.56 & 1.52 & 1.61 & 1.43 & 1.24 & 1.65 & 1.44 & 1.41 & 1.47 & 1.65 & 1.47 & 1.85 \\
\hline \multirow[t]{3}{*}{ Smoking habits } & Never smoked & 1 & - & - & 1 & - & - & 1 & - & - & 1 & - & - \\
\hline & Former smoker & 1.19 & 1.15 & 1.23 & 1.32 & 1.13 & 1.55 & 1.18 & 1.14 & 1.21 & 1.42 & 1.24 & 1.63 \\
\hline & Smoker & 1.24 & 1.20 & 1.29 & 1.20 & 1.04 & 1.38 & 1.26 & 1.23 & 1.29 & 1.30 & 1.14 & 1.47 \\
\hline \multirow[t]{3}{*}{ BMl } & Normal weight & 1 & - & - & 1 & - & - & 1 & - & - & 1 & - & - \\
\hline & Underweight & 1.31 & 1.16 & 1.49 & 0.77 & 0.38 & 1.59 & 1.09 & 1.04 & 1.14 & 1.22 & 0.99 & 1.51 \\
\hline & Overweight/obese & 1.01 & 0.98 & 1.04 & 1.09 & 0.96 & 1.24 & 1.09 & 1.06 & 1.11 & 0.95 & 0.85 & 1.06 \\
\hline
\end{tabular}

in developed countries the economic crisis can determine pro-cyclical effects on health, at least over the short term [36], with a protective effect on mortality - with the exception of suicides [37] - especially in countries with advanced welfare systems able to attenuate its negative effects [16].

Moreover, immigrants in Italy appears to be in better condition than reported in studies conducted in Canada $[38,39]$ and in European regions [40], particularly of north [41], where worse health conditions in immigrant than in the native population were observed. Some studies argue about vulnerability in the period after the immigration process as the result of different factors, such as living in poorer socioeconomic conditions than natives [42], and tending to assimilate lifestyles of the more socioeconomically disadvantaged population groups [43].

However, considering that immigration is a relatively recent phenomenon in Italy, which reached its apex in the first decade of the 2000's, it is difficult to make a comparison with other European countries with a more consolidated migratory tradition. In Italy, during the time of the study we did not observe relevant modifications in the distribution of the origin countries among foreign citizens. The most evident phenomenon was the increase of Romanians and Moldovans, after the entrance of Romania in European Union in 2008. It is difficult to disentangle the potential differential impact on health of the immigration composition in the two years.

Socioeconomic disparities in health among immigrants are a complex issue, involving different dimensions, including the selection of people candidate to emigrate due to the "healthy migrant effect" [44] and a life course perspective. As a consequence it is necessary to take into account different socioeconomic distribution of risk factors in the countries of origin [45] on one side, and, on the other hand, the socioeconomic career, including occupation position, in the host country that is strongly affected by educational level and by the integration process difficulties [46].

Our study shows that educational level is a strong predictor of worse health status in Italians, but weaker in immigrants, thus pointing out that this dimension does not appear to be a relevant predictor of health for immigrants in Italy, differently from what observed elsewhere [47]. It was underlined that this indicator does not allow to disentangle immigrants' socioeconomic differences in health, because it is difficult to properly compare educational qualification acquired in different countries and, also, the interpretation of educational level classification used in the survey questionnaire could differ among immigrants' origin areas [48]. In order to overcome these difficulties, other dimensions should be evaluated, such as interpersonal and institutional discrimination experienced [47, 49]. 
Self-perceived economic resources are the strongest socioeconomic predictor of worse health status for immigrants, particularly on mental health. Availability of economic resources could be the main factor generating health vulnerability in immigrants. Moreover, deeper analysis showed an interaction between economic resources and survey's edition (at the limit of statistical significance), with a stronger association with mental health in 2013 for immigrant men and women (data not shown). This finding suggests an increased role played by perceived economic position in health during the global crisis.

Not being employed is associated with worse mental health conditions among men. This result can be explained considering that a traditional family organization assigning to men the main economic responsibilities is still deeply-rooted in Italy: this role could act as a stressor increasing the risk of bad self-perceived mental health among men [26].

The present study presents some limitations. It is important to outline that our study is based on selfreported health: information on the health status referred to the individual's perception and not to an objective clinical diagnosis. However, it has clearly been shown that self-perceived health represents a reliable predictor of mortality and morbidity [50].

Furthermore, the multipurpose surveys do not include data on undocumented immigrants, a subgroup of population living at the margins of society, in the worst housing, employment and health conditions, and less integrated than regular resident immigrants. However, undocumented immigrants are estimated to be a small part of the immigration phenomenon (around 326,000, representing $0.5 \%$ of the total population), so we can speculate that this limit does not affect our results.

Another limit was the unavailability of the information on length of stay, an important confounding factor, often strongly associated with the health status of immigrants, but this variable was only recorded in 2013 edition of the survey.

Moreover, it is well known that the health of immigrants shows heterogeneous characteristics according to the area of origin [51, 52]. Unfortunately, given that in 2005 the presence of immigrants was still quite small, it was not possible to stratify the sample by area of origin, due to the lack of sufficient statistical power.

Lastly, given that the ISTAT survey is cross-sectional, it does not allow to carry out hypothesis on causal associations, which are only possible through longitudinal studies.

\section{Conclusions}

To our knowledge, this is the first national study that analyses the health status of the Italian and immigrant resident population and investigates the effects of socioeconomic conditions. As we had the availability of 2005 and 2013 data, a period overlapping with the great global economic crisis, we can hypothesised that the observed decline in mental health could be a consequence of the worsening of socioeconomic conditions, particularly relevant among immigrants.

This is an issue to be carefully monitored in a context of resource's limitation introduced in public health policies due to financial crisis, such as increased medical co-pay fees and the reduction of essential medical services provided by the Italian National Health System.

Policy decision makers and health service managers must face the challenge of the reduction of socioeconomic inequalities in health and in access to health care. Acting to reduce health inequalities means to address to a fair society [53].

\section{Abbreviations}

INMP: National Institute for Health, Migration and Poverty; ISTAT: Italian National Institute of Statistics; MCS: Mental Component Summary; OENIP: National Epidemiologic Observatory on Immigrants and Poverty; PAPI: Paper and Pencil Interview; PCS: Physical Component Summary; PRR: Prevalence rate ratios

\section{Acknowledgements}

We thank Cecilia Fazioli for the English language translation.

\section{Funding}

No funding to declare.

\section{Availability of data and materials}

The analyses were performed using data based on ISTAT's surveys. In particular, we used ISTAT's standard files (issued upon request with a valid reason for research purposes and released free of charge and in compliance with the principle of statistical secrecy and protection of personal data). To acquire such files it is necessary to register at the area of the ISTAT website dedicated to them and to accept the terms of use. Data are available in different formats (TXT, STATA, SAS, R).

\section{Authors' contributions}

$A P$ and ADN designed and initiated the study, researched the data and wrote the manuscript. AR contributed to the statistical analyses and reviewed/edited the manuscript. GC, CM and LG contributed to the discussion and critically reviewed the final manuscript. LG and AP are the guarantors of this work. All authors read and approved the final manuscript.

\section{Competing interests}

No competing interests were reported by the authors of this paper.

Consent for publication

Not applicable.

Ethics approval and consent to participate

The multipurpose survey "Health conditions and use of health services" was part of the activities included in the 2011-2013 National Statistical Programme (http://www.sistan.it/index.php?id=120), PSN code: IST-02067 approved by the Italian Presidency of the Council of Ministers (decrees dated 31 March 2011 and 20 April 2012). A total of 60,368 de-facto households were randomly selected within 1456 nationally-representative municipalities. The selected households were informed by letter from the Italian National Institute of Statistics about the purposes and the modalities of conduction of the survey. They were also reassured about confidentiality and protection of personal data (Italian legislative decree n. 196/2003). Except for some sensitive information specified in the 
informative letter, the response to the survey was mandatory by law (Art. 7 of the Italian legislative decree n. 322/1989 and Italian presidential decree dated 26 September 2012) and formal consent to participate was therefore not required.

\section{Publisher's Note}

Springer Nature remains neutral with regard to jurisdictional claims in published maps and institutional affiliations.

\section{Author details}

'National Institute for Health, Migration and Poverty (INMP), Via San Gallicano, 25 a, 00153 Rome, Italy. ${ }^{2}$ National Institute of Statistics (ISTAT), Viale Liegi, 13, 00198 Rome, Italy.

Received: 13 January 2017 Accepted: 6 June 2017

Published online: 12 June 2017

\section{References}

1. Ministero Dell'Interno. Available from: http://www.interno.gov.it/it/notizie/ line-dati-e-statistiche-sui-migranti-italia. Accessed 7 Apr 2017.

2. ISTAT. Demo-Geodemo. - Maps, Population, Demography of ISTAT - Italian Institute of Statistics. http://demo.istat.it/index_e.html. Accessed 7 Apr 2017.

3. ISMU. Ventunesimo rapporto sulle migrazioni 2015. Angeli F, editor. Milano, Italy; 2015.

4. Boulogne R, Jougla E, Breem Y, Kunst AE, Rey G. Mortality differences between the foreign-born and locally-born population in France (20042007). Soc Sci Med. 2012;74:1213-23.

5. Razum O, Zeeb H, Rohrmann S. The "healthy migrant effect" - not merely a fallacy of innacurate denominator figures. Int J Epidemiol. 2000;29:191-2.

6. Norredam M, Agyemang C, Hoejbjerg Hansen OK, Petersen JH, Byberg S, Krasnik $A$, et al. Duration of residence and disease occurrence among refugees and family reunited immigrants: Test of the "healthy migrant effect" hypothesis. Trop Med Int Heal. 2014;19:958-67.

7. Ullmann SH, Goldman N, Massey DS. Healthier before they migrate, less healthy when they return? The health of returned migrants in Mexico. Soc Sci Med. 2011:73:421-8.

8. Vandenheede H, Willaert D, De Grande H, Simoens S, Vanroelen C. Mortality in adult immigrants in the 2000s in Belgium: a test of the "healthy-migrant" and the "migration-as-rapid-health-transition" hypotheses. Trop Med Int Heal. 2015;20:1832-45.

9. Uitenbroek DG. Mortality trends among migrant groups living in Amsterdam. BMC Public Health. 2015;15:1187. doi:10.1186/s12889-015-2523-6.

10. Giannoni M, Franzini L, Masiero G. Migrant integration policies and health inequalities in Europe. BMC Public Health. 2016;16:463. doi:10.1186/s12889 016-3095-9.

11. Gimeno-Feliu LA, Calderón-Larrañaga A, Diaz E, Poblador-Plou B, MacipeCosta $R$, Prados-Torres $A$. The healthy migrant effect in primary care. Gac Sanit. 2015;29:15-20.

12. De Maio FG. Immigration as pathogenic: a systematic review of the health of immigrants to Canada. Int J Equity Health. 2010;9:27. doi:10.1186/14759276-9-27.

13. Acevedo-Garcia D, Bates LM, Osypuk TL, McArdle N. The effect of immigrant generation and duration on self-rated health among US adults 2003-2007. Soc Sci Med. 2010;71:1161-72.

14. Vlachadis N, Vlachadi M, Iliodromiti Z, Kornarou E, Vrachnis N. Greece's economic crisis and suicide rates: overview and outlook. J Epidemiol Community Health. 2014;68(12):1204-5.

15. ISTAT. II mercato del lavoro negli anni della crisi. Dinamiche e divari. Rapporto Annuale. 2014. p. 81-138.

16. Marmot M. How will the financial crisis affect health? BMJ. 2009;338:b1314

17. Hopkins S. Economic stability and health status: evidence from East Asia before and after the 1990s economic crisis. Health Policy. 2006;75:347-57.

18. Bacigalupe A, Escolar-Pujolar A. The impact of economic crises on social inequalities in health: what do we know so far? Int J Equity Health. 2014;13: 52. doi:10.1186/1475-9276-13-52.

19. Bartoll X, Palencia L, Malmusi D, Suhrcke M, Borrell C. The evolution of mental health in Spain during the economic crisis. Eur J Public Health. 2014;24:415-8.

20. Eurofound. Access to healthcare in times of crisis. Luxembourg: Publications Office of the European Union; 2014.
21. Kunst AE, Groenhof F, Mackenbach JP, Health EW. Occupational class and cause specific mortality in middle aged men in 11 European countries: comparison of population based studies. EU Working Group on Socioeconomic Inequalities in Health. BMJ. 1998;316:1636-42.

22. Avendano M, Kunst AE, Huisman M, Lenthe FV, Bopp M, Regidor $E$, et al. Socioeconomic status and ischaemic heart disease mortality in 10 western European populations during the 1990s. Heart. 2006;92:461-7.

23. Mackenbach J, Stirbu I, Roskam A, Schaap M, Menvielle G, Leinsalu M, et al. Socioeconomic inequalities in health in 22 European countries. N Engl J Med. 2008;358:2468-81.

24. Dalstra JAA, Kunst AE, Borell C, Breeze E, Cambois E, Costa G, et al. Socioeconomic differences in the prevalence of common chronic diseases: an overview of eight European countries. Int J Epidemiol. 2005:34:316-26.

25. Hemingway $H$, Nicholson A, Stafford $M$, Roberts $R$, Marmot $M$. The impact of socioeconomic status on health functioning as assessed by the SF-36 questionnaire: the Whitehall II Study. Am J Public Health. 1997;87:1484-90.

26. Artazcoz L, Benach J, Borrell C, Cortès I. Unemployment and mental health: understanding the interactions among gender, family roles, and social class. Am J Public Health. 2004:94:82-8.

27. Sareen J, Afifi TO, McMillan KA, Asmundson GJG. Relationship between household income and mental disorders. Arch Gen Psychiatry. 2011:68:419-27.

28. Catalano R, Goldman-Mellor S, Saxton K, Margerison-Zilko C, Subbaraman M, LeWinn $\mathrm{K}$, et al. The health effects of economic decline. Annu Rev Public Health. 2011;32:431-50. doi:10.1146/annurev-publhealth-031210-101146.

29. Pacelli B, Zengarini N, Broccoli S, Caranci N, Spadea T, Di Girolamo C, et al. Differences in mortality by immigrant status in Italy. Results of the Italian Network of Longitudinal Metropolitan Studies. Eur J Epidemiol. 2016;31:691-701.

30. Cacciani L, Asole S, Polo A, Franco F, Lucchini R, De Curtis M, et al. Perinatal outcomes among immigrant mothers over two periods in a region of central Italy. BMC Public Health. 2011:11:294. doi:10.1186/1471-2458-11-294.

31. Bena A, Giraudo M. Occupational injury risk in immigrant workers in Italy: differences in work characteristics and age. Epidemiol Prev. 2014;38:208-18.

32. ISTAT. http://siqual.istat.it/SIQual/visualizza.do?id=0071201. Accessed 7 Apr 2017.

33. Ware Jr JE, Kosinski M, Bayliss MS, McHorney CA, Rogers WH, Raczek A. Comparison of methods for the scoring and statistical analysis of SF-36 health profile and summary measures: summary of results from the Medical Outcomes Study. Med Care. 1995;33:AS264-79.

34. Barbaglia MG, ten Have M, Dorsselaer S, Alonso J, de Graaf R. Negative socioeconomic changes and mental disorders: a longitudinal study. J Epidemiol Community Health. 2015;69:55-62.

35. Gotsens M, Malmusi D, Villarroel N, Vives-Cases C, Garcia-Subirats I, Hernando $C$, et al. Health inequality between immigrants and natives in Spain: the loss of the healthy immigrant effect in times of economic crisis. Eur J Public Health. 2015;25(6):923-9.

36. Suhrcke $M$, Stuckler D. Will the recession be bad for our health? It depends. Soc Sci Med. 2012;74:647-53.

37. Toffolutti $V$, Suhrcke M. Assessing the short term health impact of the great recession in the European Union: a cross-country panel analysis. Prev Med. 2014;64:54-62.

38. Kim IH, Carrasco C, Muntaner C, McKenzie K, Noh S. Ethnicity and postmigration health trajectory in new immigrants to Canada. Am J Public Health. 2013;103:96-104

39. Subedi RP, Rosenberg MW. Determinants of the variations in self-reported health status among recent and more established immigrants in Canada. Soc Sci Med. 2014;115:103-10.

40. Nielsen SS, Krasnik A. Poorer self-perceived health among migrants and ethnic minorities versus the majority population in Europe: a systematic review. Int J Public Health. 2010;55:357-71.

41. Jervelund SS, Malik S, Ahlmark N, Villadsen SF, Nielsen A, Vitus K. Morbidity, Self-Perceived Health and Mortality Among non-Western Immigrants and Their Descendants in Denmark in a Life Phase Perspective. J Immigr Minor Health. 2017:19:448-476. doi:10.1007/s10903-016-0347-9.

42. Spallek J, Zeeb H, Razum O. What do we have to know from migrants' past exposures to understand their health status? a life course approach. Emerg Themes Epidemiol. 2011;8:6. doi:10.1186/1742-7622-8-6.

43. Lara M, Gamboa C, Kahramanian MI, Morales LS, Bautista DEH. Acculturation and Latino health in the United States: a review of the literature and its sociopolitical context. Annu Rev Public Health. 2005:26:367-97.

44. Goldman N, Kimbro RI, Turra CM, Pebley AR. Socioeconomic gradients in health for white and Mexican-origin populations. Am J Public Health. 2006; 96:2186-93. 
45. Bennet L, Agardh C-D, Lindblad U. Cardiovascular disease in relation to diabetes status in immigrants from the Middle East compared to native Swedes: a cross-sectional study. BMC Public Health. 2013;13:1133. doi:10. 1186/1471-2458-13-1133.

46. Stronks K, Kunst AE. The complex interrelationship between ethnic and socio-economic inequalities in health. J Public Health. 2009;31:324-5.

47. Dinesen C, Nielsen SS, Mortensen LH, Krasnik A. Inequality in self-rated health among immigrants, their descendants and ethnic Danes: Examining the role of socioeconomic position. Int J Public Health. 2011;56:503-14.

48. Dunlavy AC, Garcy AM, Rostila M. Educational mismatch and health status among foreign-born workers in Sweden. Soc Sci Med. 2016;154:36-44.

49. Karlsen S, Nazroo J. Relation between racial discrimination, social class, and health among ethnic minority groups. Am J Public Health. 2002;92:624-31.

50. Idler EL, Benyamini Y. Self-rated health and mortality: a review of twentyseven community studies. J Health Soc Behav. 1997:38:21-37.

51. Rechel B, Mladovsky P, Ingleby D, Mackenbach JP, McKee M. Migration and health in an increasingly diverse Europe. Lancet. 2013;381:1235-1245.

52. Lanari D, Bussini O, Minelli L. Self-perceived health among Eastern European immigrants over 50 living in Western Europe. Int J Public Health. 2015;60:21-31.

53. Marmot M. Public health social determinants of health inequalities. Lancet. 2005:365:1099-104.

Submit your next manuscript to BioMed Central and we will help you at every step:

- We accept pre-submission inquiries

- Our selector tool helps you to find the most relevant journal

- We provide round the clock customer support

- Convenient online submission

- Thorough peer review

- Inclusion in PubMed and all major indexing services

- Maximum visibility for your research

Submit your manuscript at www.biomedcentral.com/submit
Biomed Central 